\title{
Agriculture, plant physiology, and human population growth: past, present, and future
}

\section{Lincoln Taiz}

University of California, Santa Cruz, CA, United States of America.

*Corresponding author: Itaiz@ucsc.edu

Received: 24 August 2013; Accepted: 26 August 2013
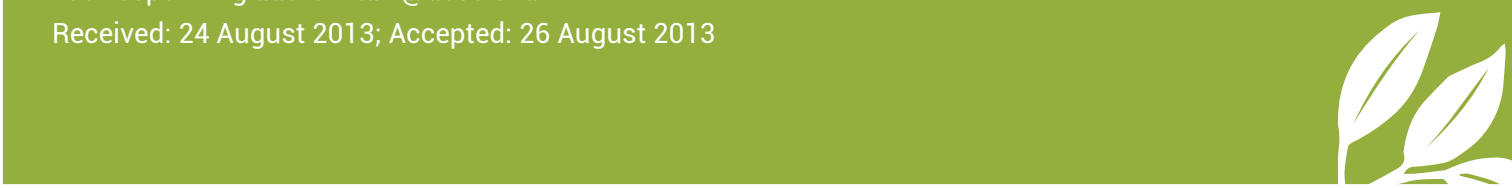

When we gaze at our beautiful blue planet as seen from space (Figure 1A), it's difficult to believe that a single species could have such a profound impact on earth's climate, but that is exactly what is happening. To put it bluntly, we humans have been too creative and too reproductively successful for our own good (Figure 1B), and our success has brought about the four major challenges we face today: loss of biodiversity, pollution, climate change, and food insecurity.

If we examine human population growth, modern humans evolved around 200,000 years ago, and for most of that time they survived as hunter-gatherers. By 8,000 BC, the population increased to about 10 million people. The invention of agriculture eventually led to urbanization, and the population had grown to 50 million by the Bronze Age. By the time of Christ, the population had increased to 250 million, before reaching its first billion by the middle of the eighteenth century. After that, the human population increased to seven billion in just two hundred years. By 2050, if all goes well, we're supposed to finally level off at about nine billion.

In 1798, when the human population was "only" one billion, the British cleric Thomas Malthus published his famous Essay on the Principle of Population, in which he compared the geometric growth of human populations to the arithmetic growth of the food supply and predicted that population growth would soon outstrip our ability to feed ourselves. Malthus was wrong for a couple of reasons: First, he underestimated human resourcefulness and second, he did not anticipate modern birth control methods. Contrary to his predictions, food production has not only kept up with population growth, but also has become a driver of population growth (Evans 1998).

As noted by Jared Diamond, the author of Guns, Germs, and Steel, agriculture is "an autocatalytic process, that catalyzes itself in a positive feedback cycle." Each major advance in agriculture was accompanied by an increase in the rate of population growth. Mazoyer and Roudart (2006) identified three major inflection points (Figure 1C): first, the Neolithic agricultural revolution, which began at around 8,000 BC; the Neolithic Revolution was, without question, the golden age of crop creation, the most radical phase of agriculture, which brought more drastic changes to wild species than has since been achieved by scientific plant breeding and genetic engineering. Second, the hydroagricultural or irrigation revolutions in the Near East, which began around 3,000 BC. Third, the medieval and modern agricultural periods, which began around 1,000 AD.

Let us examine the relationship between agriculture and population in a little more detail, beginning with the agricultural revolution, which enabled the population to increase to 50 million.

For reasons that are still poorly understood, modern humans began to live in permanent settlements located near abundant wild food supplies around 8,000 BC (Figure 2). They soon began planting gardens, and this led to the domestication of three types of staple crops - cereals, legumes, and roots or tubers. The earliest domesticated food crops were in the Fertile Crescent and included Emmer and Einkorn wheat, barley, pea, lentil, chickpea, and bitter 

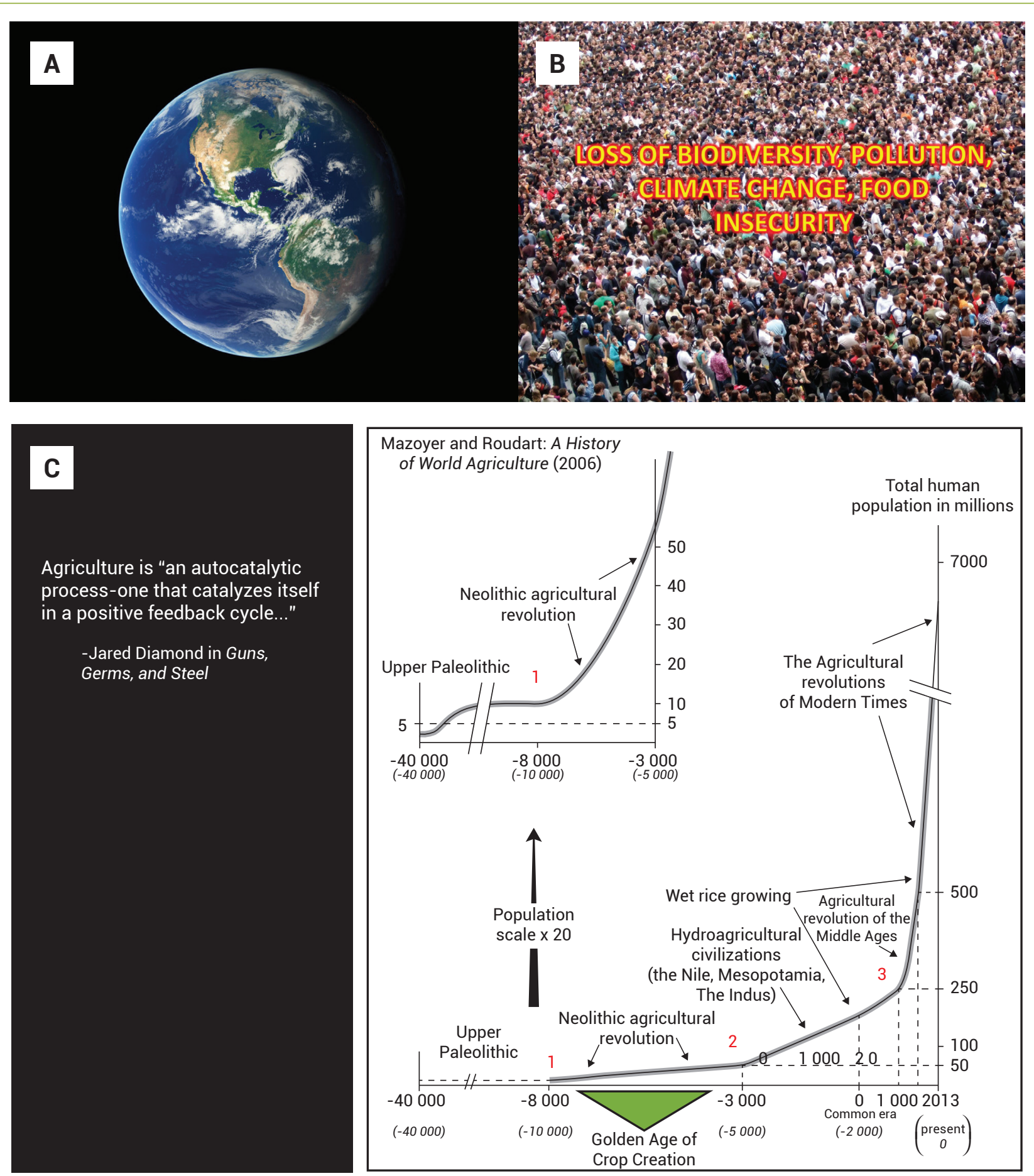

Figure 1. Agriculture and population growth. (A) The earth as seen from space (NASA); (B) Big crowds provide a metaphor for overpopulation (http://lookingtobusiness.com/wp-content/uploads/2010/11/A-picture-of-a-crowd-of-people.jpg); (C) Major inflection points in the growth of human population correlated with the development of agriculture (from Mazoyer and Roudart, 2006, p. 65). 


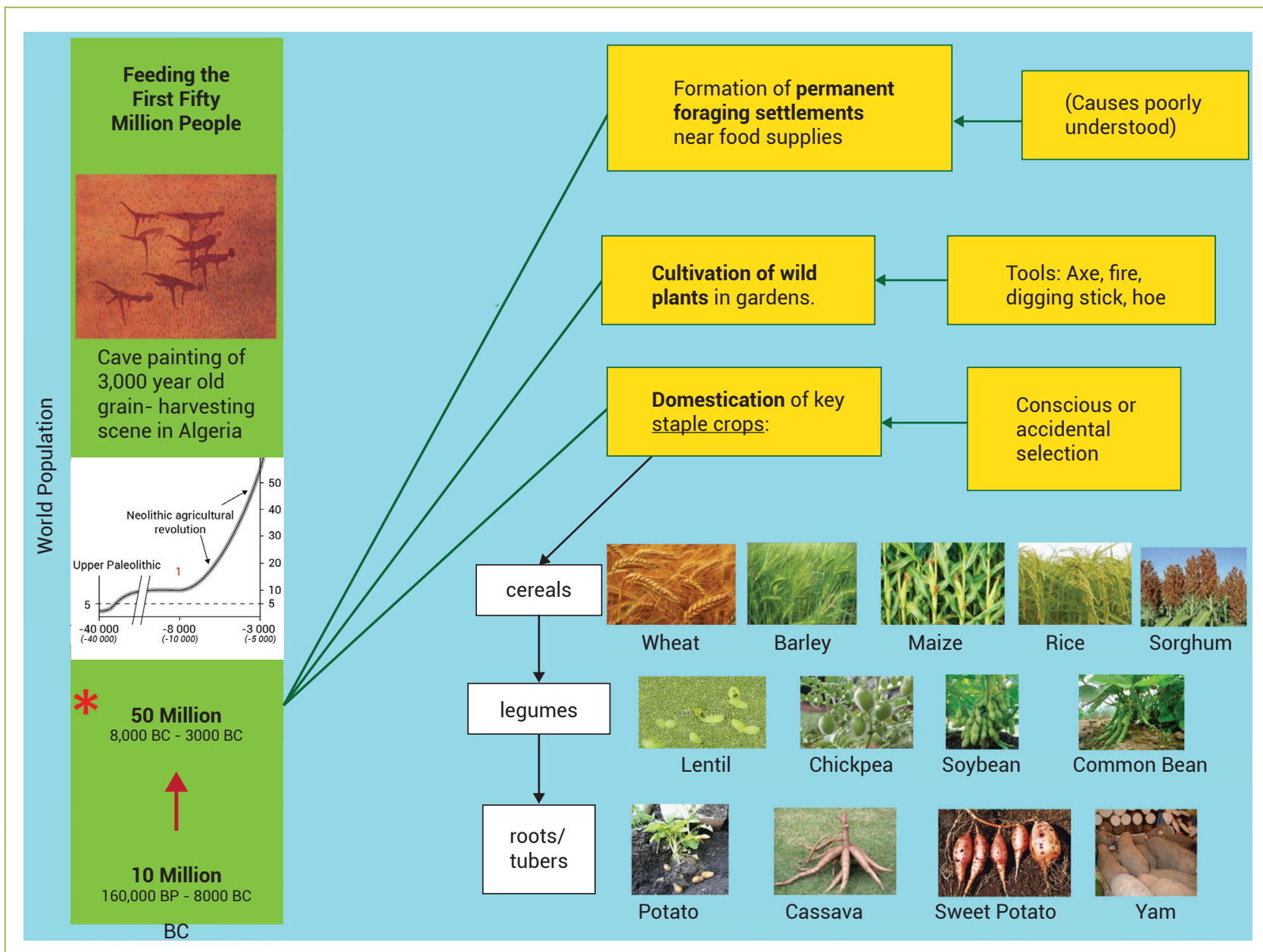

Figure 2. Feeding 50 million people.

vetch. The combination of cereals and legumes provided all the essential amino acids needed for human nutrition.

Agriculture arose independently at least seven times around the world - between 10,000 and 4,000 years ago. Each of these seven major centers of domestication involved its own suite of crop species. For example, rice and millet were the primary domesticates in Asia; sorghum was domesticated in Africa; maize, squash, and beans were domesticated in Mexico; South America gave us the potato and sweet potato; and North America domesticated sunflowers. Domestication typically involved selecting some or all of the following genetic traits: increased reproductive output, non-dehiscent fruits, self-pollination, larger seeds and fruits, loss of seed dormancy, rapid and uniform germination, uniform ripening, annual life cycle, and palatability. For example, during wheat domestication, there was unconscious selection for mutants with non-shattering ears that would not fall apart during harvesting. You can easily recognize the wild forms because the spikelets have smooth abscission zones. In contrast, the spikelets of domesticated wheat varieties all have rough surfaces where the rachis breaks during threshing. In addition, the domesticated wheat varieties have larger seeds and germinate more rapidly and uniformly than the wild variety.

Polyploidy played crucial roles in the evolution of domesticated wheat. Einkorn was diploid, Emmer and Durum wheats were tetraploid, and the bread wheats were hexaploid. First, the diploid Einkorn wheat hybridized with the diploid Aegilops, or goat grass, followed by polyploidization to produce the tetraploid Durum wheat, composed of two different diploid genomes, AA and BB. Next, Durum wheat hybridized with another diploid goat grass to produce a triploid hybrid, followed by yet another polyploidization event to produce the hexaploid bread wheat, with three diploid genomes - AA, BB, and DD.

Domesticated maize evolved from one of the teosintes: Zea mays ssp. parviglumis. There are four subspecies of Zea mays: huehuetenangensis, mexicana, parviglumis, and mays. 
The first three are the teosintes, and domesticated maize is Zea mays ssp. mays. The transformation of teosinte into maize was one of the most dramatic changes in the history of plant domestication. The major change was the fasciation of the teosinte inflorescence, giving rise to the maize cob with its numerous rows of kernels. Recent studies by Bommert et al. (2013) have identified the FASCIATED EAR2 locus, which regulates the number of rows of kernels in maize cobs. Genes that regulate fasciation could potentially increase the yields of other cereals. Imagine, for example, a cob of wheat!

Between about 3,000 BC and $800 \mathrm{AD}$, the population grew fivefold from 50 million to 250 million people (Figure 3). How did agriculture keep pace with this population growth? During this period, agriculture spread from its seven centers of domestication throughout Eurasia and the Americas. As more and more people began farming, more and more land was cleared and cultivated. Oxen, and later horses, were harnessed to plows for the first time, greatly increasing the efficiency of cultivation. Farmers learned to fertilize their soils with animal manure and by planting legumes, the so-called green manures. Crop rotation and fallowing were also practiced for the first time. Irrigation gave rise to the great Bronze Age civilizations of Mesopotamia and Egypt. Many new perennial crops, especially fruit and nut trees and vines, were domesticated. Unlike the annual crops, the perennial crops were mostly outcrossers, so they would not breed true from seed. Therefore, they had to be propagated vegetatively or by grafting. In the case of dioecious species, such as figs, dates, and pistachios, artificial pollination was practiced. Thus, the art of horticulture was born. This was also the period when most of our delicious vegetables were domesticated in both the Old and New Worlds, providing important nutritional benefits and dietary variety.

Between $800 \mathrm{AD}$ and 1825 (a thousand years), the population quadrupled in size to one billion people (Figure 4). During this period, crops became globalized by two important historical events. First, the spread of Islam brought Asian and African crops to Europe, and vice versa. Second, the arrival of Columbus in the New World led to an exchange of New World

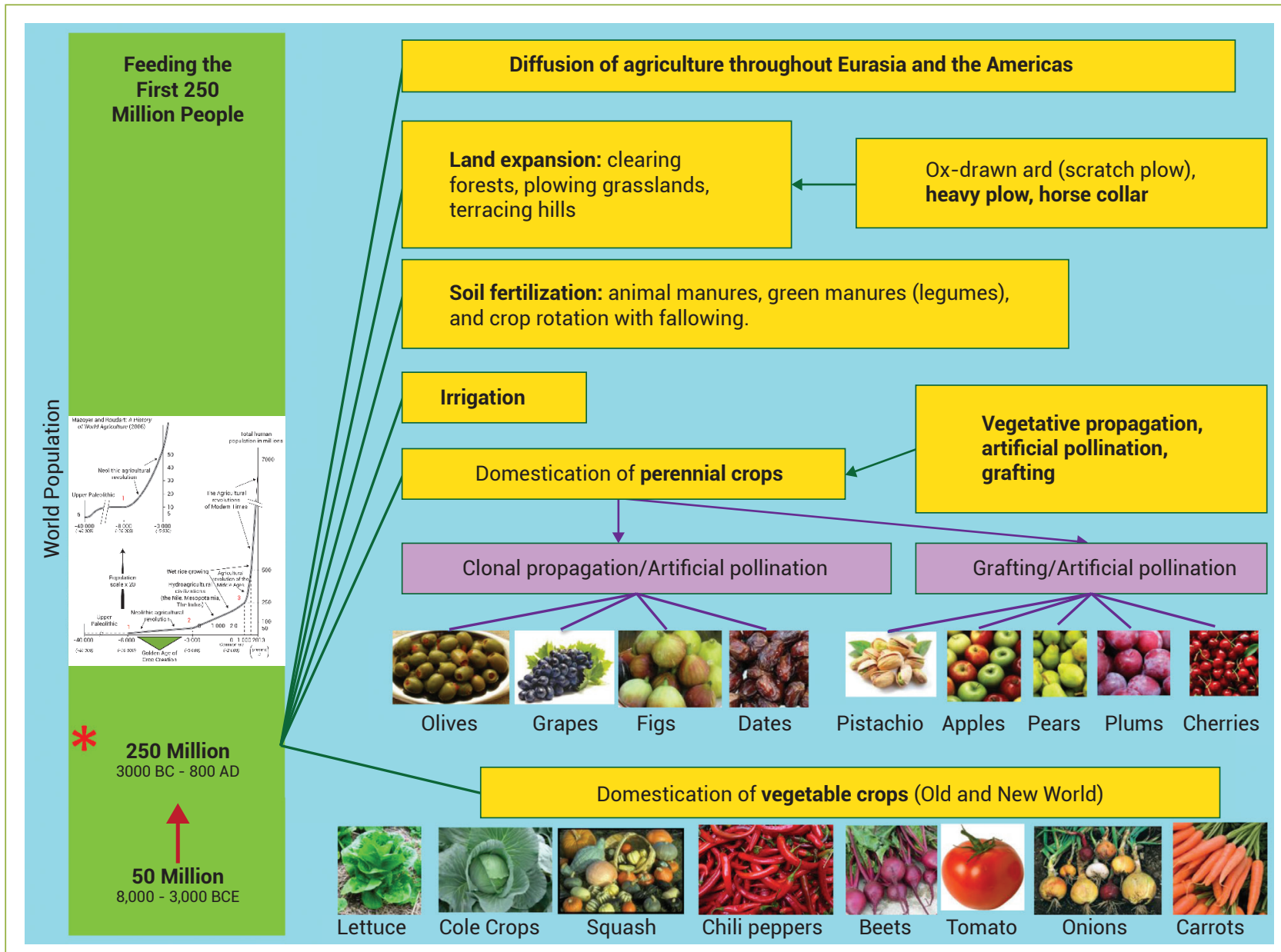

Figure 3. Feeding 250 million people. 


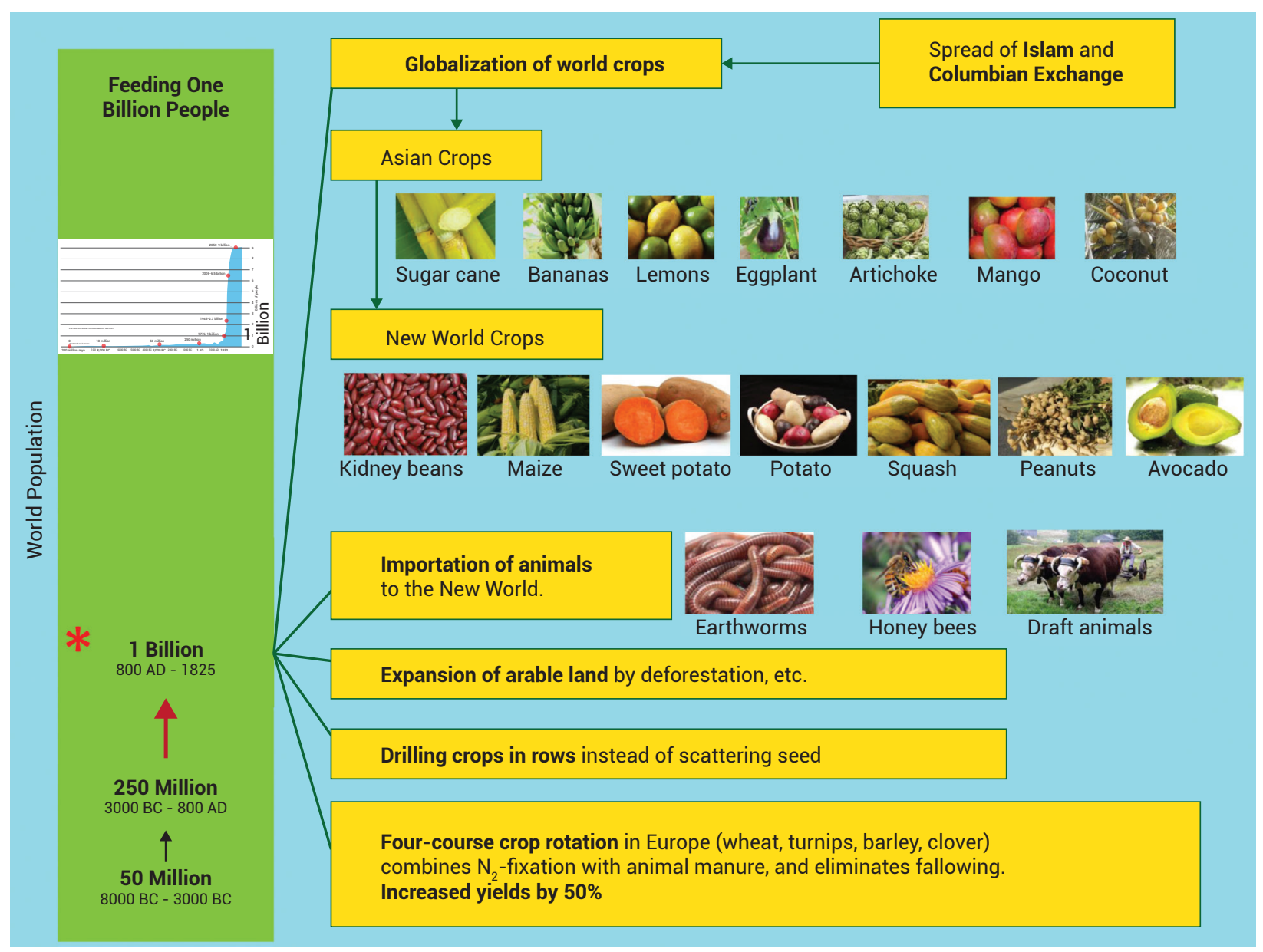

Figure 4. Feeding the first billion people.

and European crops known as the "Columbian Exchange." In addition to livestock - such as cattle, pigs, sheep, goats, and chickens - Europeans brought other animals to the New World that greatly facilitated agriculture. For example, earthworms, which had died out in the northeastern United States during the last ice age, transformed the forests of New England by digesting all the surface litter, to which the trees had been adapted. They also conditioned the soil for future cultivation by introducing air and organic matter. The importation of European honey bees, which are pollination generalists, ensured that the newly arrived Old World crops would be pollinated, and imported draft animals provided the power for plowing the land.

Particularly in the New World, this was a period in which there was considerable expansion of arable land by deforestation and the plowing of grasslands. Crop yields were further enhanced by the practice of drilling crops in rows, instead of by scattering seed. A four-course system of rotation was adopted in England and elsewhere: wheat and barley were alternated with turnips and clover, with turnips being used as animal feed (resulting in the production of manure) and clover enriching the soil through nitrogen fixation. The four-course rotation procedure increased yields by about $50 \%$.

It took 200,000 years for the human population to reach one billion people, but only a hundred years to go from one to two billion in 1927 (Figure 5). The most important factor enabling the food supply to keep pace with population growth was farmland expansion. During this period, there was a doubling of the land cleared for agriculture in the United States and a tripling of the arable land in Russia. Wheat production spread westward between 1839 and 1909. This westward expansion was made possible by extensive breeding programs, which created new wheat varieties that could be grown in these regions, resulting in an eightfold increase in US wheat production.

This same period also saw the beginning of agricultural science. Major gains in crop yields were achieved as a result of increased 


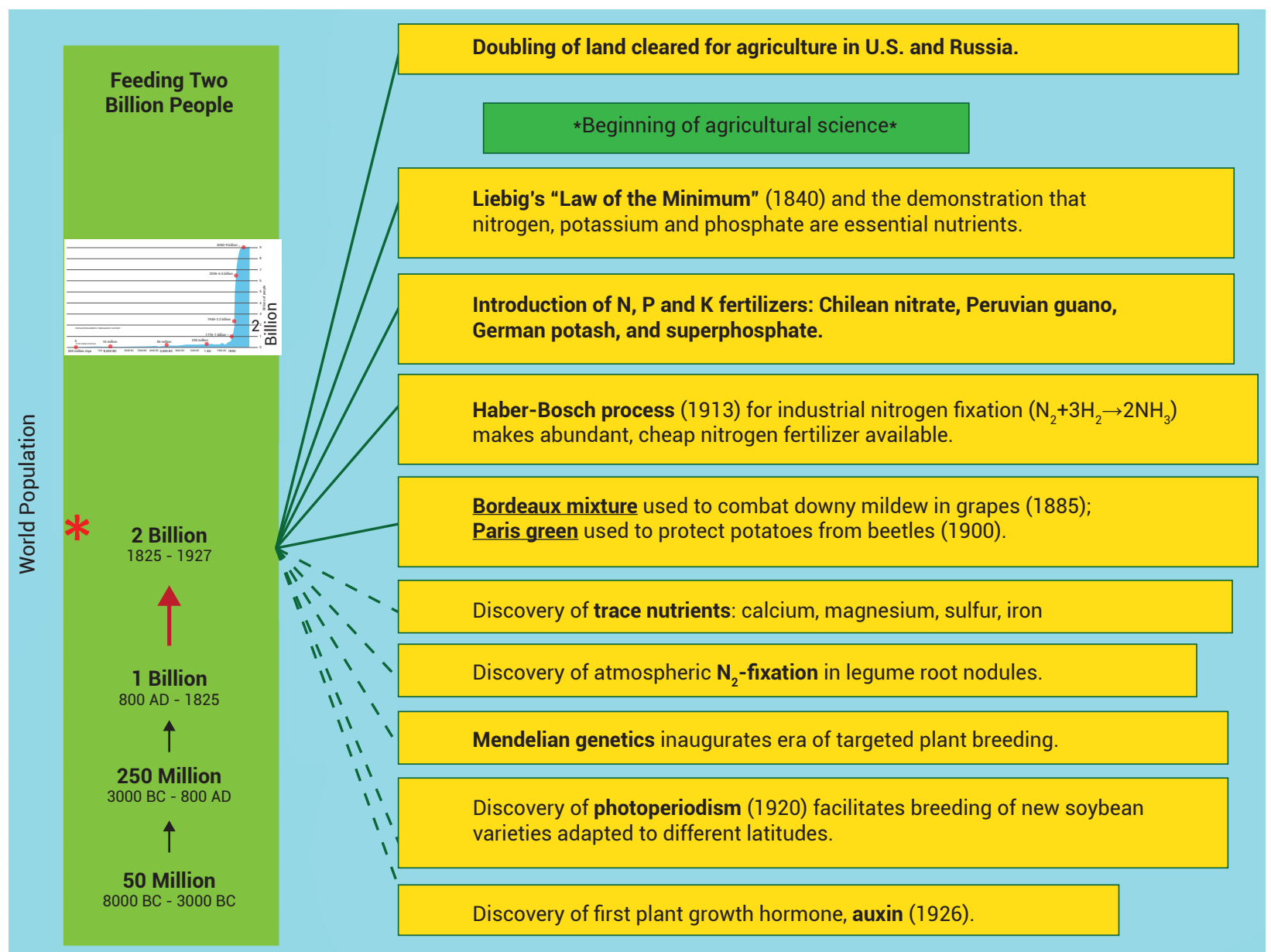

Figure 5. Feeding two billion people.

scientific understanding of plant nutrition and disease resistance. An important breakthrough was Liebig's demonstration that nitrogen, potassium, and phosphate were essential nutrients. Liebig's "Law of the Minimum," published in 1840, which stated that crop yields are always limited by the essential nutrient in shortest supply, came as a revelation to farmers who had assumed that soil fertility mainly depended on the amount of nitrogen. Of course, nitrogen was the limiting factor for soil fertility in most cases; so the importation of nitrogen-rich fertilizers from the New World in the form of Chilean nitrate and Peruvian guano greatly increased crop yields in Europe, as did German potash, or potassium salts, and superphosphate, a soluble form of phosphate. By the early twentieth century, however, the supply of cheap nitrogen fertilizer from South America was beginning to decline. Fortunately, the Haber-Bosch process for industrial nitrogen fixation came along in 1913, providing a virtually unlimited supply of cheap nitrogen fertilizer for farming. The other breakthrough came in the form of copper-based fungicides and insecticides, both of which were pioneered in France: Bordeaux mixture was first used to protect grapes from downy mildew, and Paris Green, once used to kill rats in Paris sewers, was found, at lower concentrations, to protect crops, like apples, from insect pests.

In addition to the practical gains from fertilizing and the chemical control of pests and diseases, important theoretical advances laid the foundation for future increases in crop yields. These include the identification of several trace elements (calcium, magnesium sulfur, and iron); the discovery of nitrogen fixation in legume root nodules; the advent of Mendelian genetics, which greatly accelerated the process of plant breeding; the discovery of photoperiodism, which facilitated breeding for new varieties adapted to different latitudes; and the discovery of the first plant hormone, auxin.

The population went from two billion to three billion from 1927 to 1960, and this time it took only 33 years to add another billion people (Figure 6). A huge increase in arable farmland during this period made it possible to feed all those 


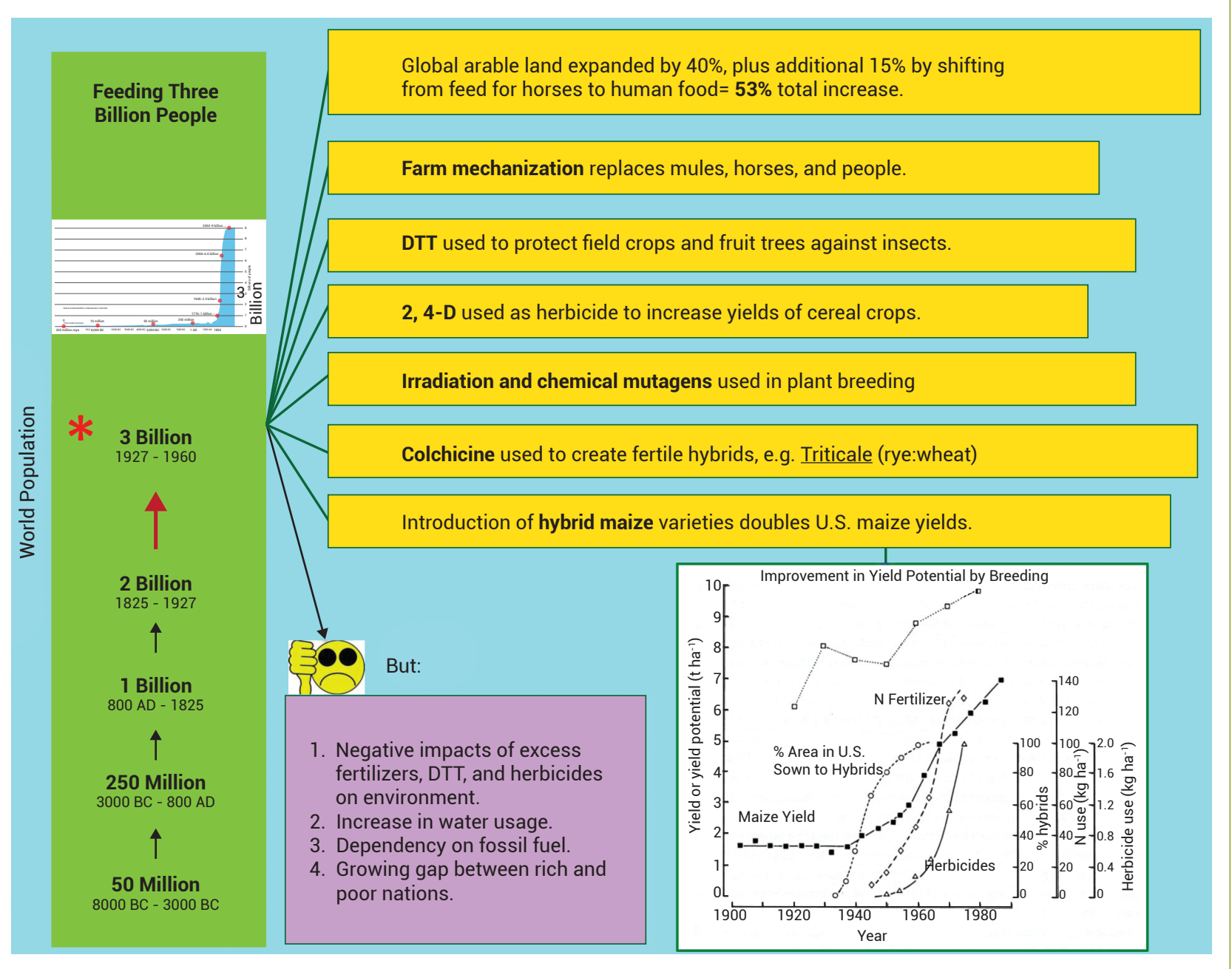

Figure 6. Feeding three billion people.

hungry mouths. The total arable land for food increased during this period by a total of 53\%. The twentieth century's greatest expansion of farmland took place in Brazil, where the arable land increased tenfold between 1900 and 1950. Farm mechanization also enabled farms to be more efficient and productive, replacing mules, horses, and people. The insecticide DTT was introduced to protect crops from insects. DTT was extremely effective and much less toxic than the older insecticides. And the synthetic auxin 2,4-D was widely used as an herbicide for cereal crops. Plant breeders also began to use irradiation and chemical mutagens to speed up the selection process; and colchicine was introduced to induce polyploidy and create new fertile hybrids, such as the wheat/rye hybrid Triticale. Finally, hybrid maize was introduced, doubling US maize yields over this period.

But there were some negative environmental impacts of these advances as well. In her influential book Silent Spring, naturalist Rachel Carson brought the toxic effects of DTT to the public's attention in 1962. The overuse of herbicides was also a problem, as was the overapplication of fertilizers, which got into the water supply and caused algal blooms. Increased water usage for irrigation led to the overpumping of aquifers, while farm mechanization and the liberal use of fertilizers both consumed large amounts of fossil fuel. Perhaps most troubling, the growing cost of modern agriculture began to open up a huge gap in food availability between rich and poor nations.

The world population reached four billion in 1975, and this time it only took 15 years to add the next billion people (Figure 7). The biggest gain in food supply was the result of the so-called Green Revolution. The term "Green Revolution" refers to the introduction in the 1960s of high-yielding, semidwarf varieties of wheat and rice. These semi-dwarf varieties responded to nitrogen fertilizer without lodging and were disease resistant as well. Historically, fully mature wheat stalks were as tall as the workers who harvested them. In contrast, the semi-dwarf varieties developed by Norman Borlaug and his colleagues in Mexico are knee-high. The new semi-dwarf 
varieties have a much higher harvest index, or grain to stalk ratio (Figure 7, left graph). The higher harvest indices of the new semi-dwarf varieties led to a remarkable increase in the wheat and rice yields in developing countries (Figure 7, right graph), which was all the more remarkable because it occurred with only a negligible increase in the amount of farmland.

On the negative side of the ledger, however, the new crops increased the amount of fertilizer, pesticide, and water used in agriculture still further and caused a large decrease in crop genetic diversity as well. So there were significant environmental downsides to the Green Revolution, as critics have pointed out.

Other factors that increased yields and helped to feed the four billion people were the switch to multiple cropping in many Asian countries; the introduction of glyphosate, or Roundup, as an herbicide, which was extremely effective and less environmentally hazardous than the older herbicides; the introduction of tissue culture techniques for clonal propagation; the first use of chemical selection in plant breeding, which led to the creation of Canola oil by eliminating erucic acid from Brassica napus seeds; and last but not least, the discovery of the Ti-plasmid of Agrobacterium tumefaciens by Schell, Montegu, and Chilton in 1974 set the stage for the creation of an ever-expanding list of GMO crops.

We went from four to five billion people in only 11 years, from 1975 to 1986 (Figure 8). Thanks largely to the continuing benefits of the Green Revolution, the food supply kept pace with population growth without increasing the amount of farmland. Wheat and rice yields kept pace with the increase in population. But, this increase in crop yield was accompanied by a big increase in nitrogen fertilizer use, as well as a slight increase in irrigation (Figure 8, graph). Once again, there was no significant increase in the total amount of arable land.

Promising new developments during this period included the beginning of no-till and minimum tillage agriculture, which

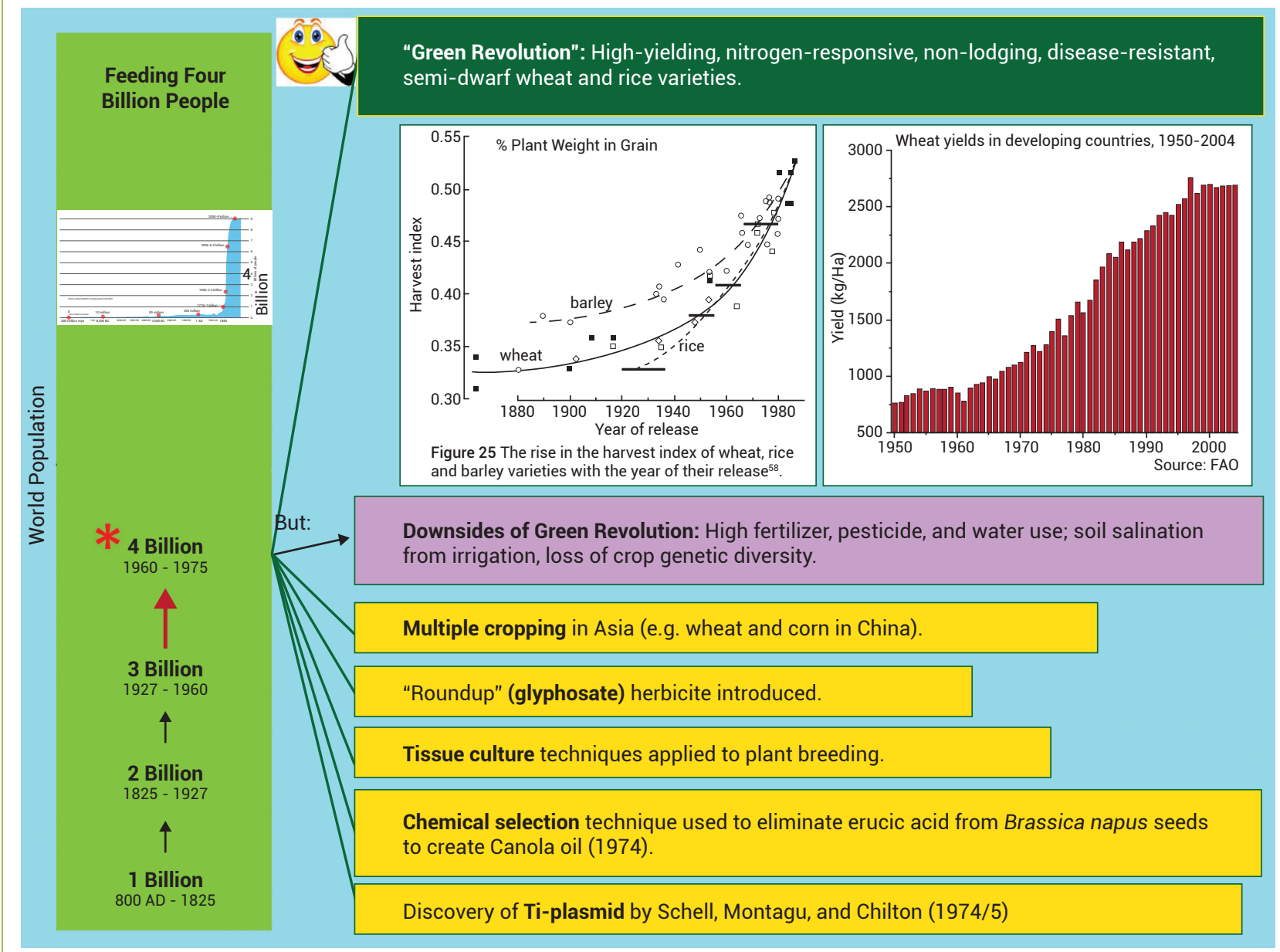

Figure 7. Feeding four billion people. 


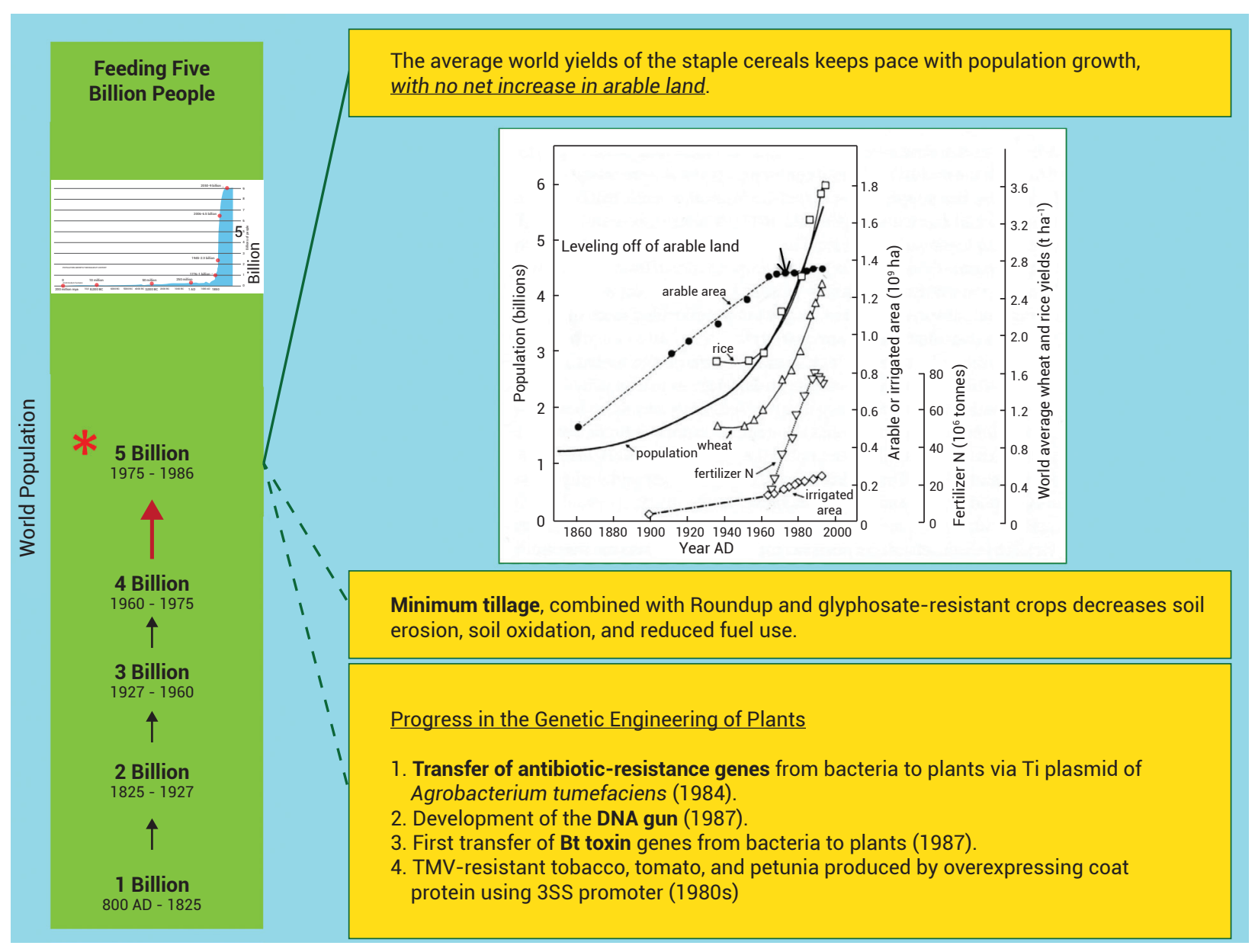

Figure 8. Feeding five billion people.

can decrease soil erosion, soil oxidation, and fuel consumption. Much progress was also made in genetic engineering during the 1980s. Plant transformation was achieved using the Ti-plasmid and the DNA gun. The bacterial gene for Bt toxin was put into plants, and the first virus-resistant plants were produced by overexpressing TMV coat protein genes using the $35 \mathrm{~S}$ promoter.

In the year 2000, it took about the same amount of time to go from five billion to six billion as it took previously to go from four billion to five billion - suggesting that the rate of population growth had finally stopped accelerating (Figure 9). This was the good news. The bad news was that we still had another billion mouths to feed. Unfortunately, the growth rate of cereal production fell to $1 \%$ per year, down from $1.6 \%$ in the 1980 s and almost $3 \%$ in the 1970 s (Figure 9, graphs). This was partly due to economic factors, and partly due to the exhaustion of the benefits derived from the Green Revolution.
More promising was the first unveiling of the first GMO crop in 1994, the "Flavr-Savr" tomato. Flavr-Savr had been transformed with the antisense gene for polygalacturonase, which inhibited cell wall softening. In theory, this would allow the tomato to ripen on the vine before being picked and shipped. However, Flavr-Savr tomatoes still softened enough during shipping to require expensive packaging, so it was withdrawn from the market in 1996.

The year 1996 saw the introduction of the first glyphosateresistant crops, which were quickly adopted by many countries around the world. In the year 2000, Ingo Potrykus and his colleagues published their paper on Golden Rice in Science. By supplying a source of vitamin A, Golden Rice holds out the promise of saving hundreds of thousands of Asian children from blindness every year. It is slowly gaining acceptance, but because of resistance to GMO foods its status as a crop is still in limbo. In 1995, the first Bt-maize crop was put on the market. By 1999, 12 million hectares of Bt maize, potato, and cotton 


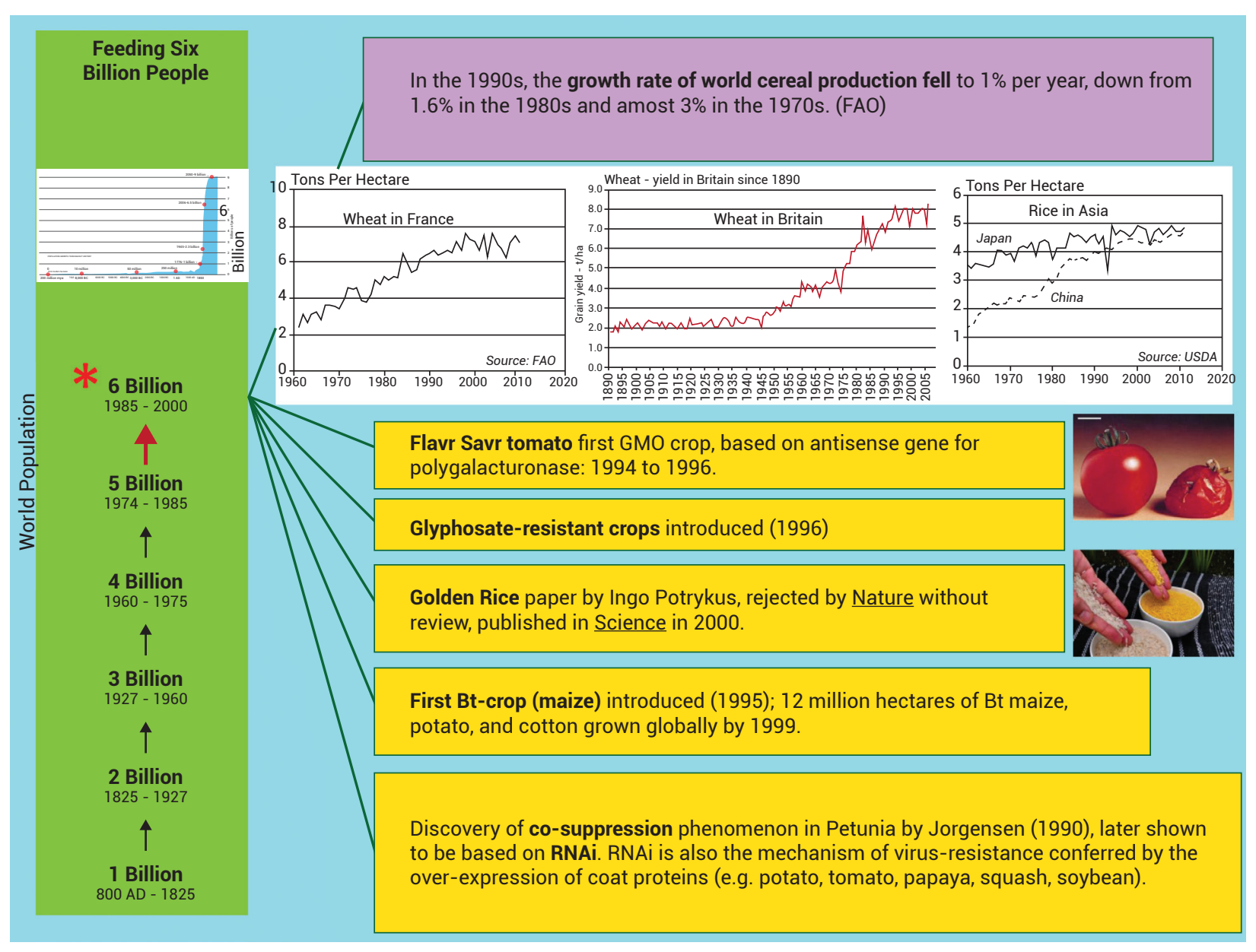

Figure 9. Feeding six billion people.

were being grown globally, significantly reducing the amount of pesticide use. In addition, co-suppression was discovered in Petunia by Jorgensen. The mechanism of co-suppression was subsequently shown to be based on RNAi, and RNAi turned out to be the basis of the virus resistance induced by overexpressing viral coat proteins. In short order, a number of virus-resistant crop plants were produced, including potato, tomato, papaya, squash, and bean.

Which brings us to 2013 (Figure 10). Today, the human population stands at about seven billion people. Although crop production is still increasing, it is increasing at a far slower rate than in the 1960s, suggesting that the benefits of the Green Revolution are effectively over. We need a new Green Revolution - a "Gene Revolution" - to boost crop yields still higher. Despite opposition in some countries, more and more farmers around the world are planting GM crops. The total land area planted in GM crops is now 100x more than it was in 1996 and is equivalent in area to the state of Alaska. The United States is still the largest planter of GM crops, with Brazil the next largest (Figure 10, left chart). An encouraging sign is that the area of land planted in GM crops in the developing world, indicated by the red curve, is now equal to that in the developed world, shown by the blue curve (Figure 10, right graph). Among the benefits of GMO crops is a decrease in pesticide use. According to Brookes and Barfoot (2010), the growing of Bt-maize alone resulted in a 35\% decrease in insecticide use between 1996 and 2008. GMO crops can also help protect against soil erosion. The use of glyphosate in conjunction with minimum tillage agriculture could prevent soil erosion and reduce greenhouse gas emission caused by soil oxidation. On the negative side of the ledger, some weeds are evolving resistance to glyphosate, and some insects are developing resistance to Bt toxins. This is simply natural selection at work and should come as no surprise. As old defenses become ineffective, new ones will have to be discovered. 


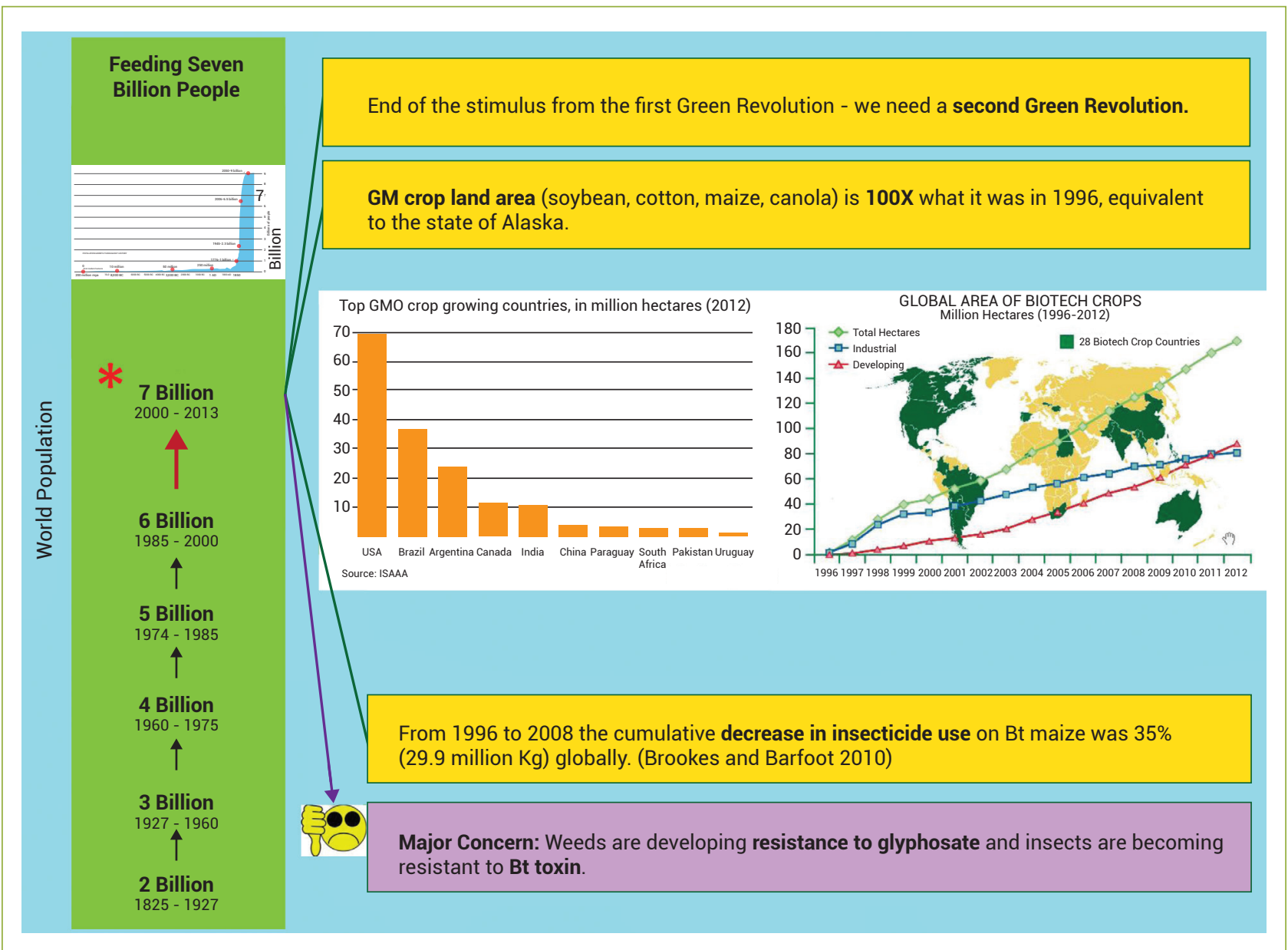

Figure 10. Feeding seven billion people.

Because of the ongoing need to feed people, agriculture dominates the planet today. Nowhere is this phenomenon more apparent than in Brazil. Brazil's agricultural output has been increasing faster than that of any other country, mostly notably in the cerrado, where farmers have converted vast stretches of grassland with acidic and nutrient-poor soils to agricultural powerhouses by the addition of lime and phosphorous. What's happening in the cerrado illustrates just how dominant agriculture is in the world today, and as with all major gains in food production it comes at an environmental cost.

According to Jonathan Foley, agriculture takes up 40\% of the global land area, which includes $12 \%$ for food crops and $28 \%$ for pastures. Agriculture also uses $70 \%$ of the global water withdrawals and generates $30 \%$ of greenhouse gases. In addition, agriculture is a major source of nitrogen and phosphorous flows in the ecosystem and a massive driver of biodiversity loss. Agriculture is thus a Faustian bargain. In the immortal words of the cartoon character Pogo, "We have met the enemy, and he is us!"

Despite the dominance of agriculture in the world today, hunger and malnutrition persist in the developing world. Nearly one billion people, about $70 \%$ of whom are located in Asia and East Africa, are malnourished according to U.N. statistics. At the same time we are in the midst of a global obesity epidemic! There are now about 1.6 billion obese people globally. The problem is that some people in the more affluent nations are eating enough food for two or three people, while others are going hungry. Unsurprisingly, Americans are the worst offenders. But as economic conditions improve and more and more people enter the middle class, they are going to want the same abundance of food that the rich nations have. They are also going to want to eat higher up on the food chain — i.e., more meat — which 
will require even greater increases in crop production to feed all the additional livestock. Trying to prevent this trend is probably a futile exercise.

To keep pace with both population growth and potential economic improvement, the prevailing opinion is that we will have to double the current rate of food production in order to feed nine billion people by 2050 (Figure 11). Can we do this? To double food production by 2050, Ray et al. (2013) have calculated that crop yields would have to grow at a rate of $2.4 \%$ per year. But the current growth rates of world crop yields for maize, rice, wheat, and soybeans are well short of $2.4 \%$. In fact, crop yields are increasing at less than half the required rate (Figure 12). How, then, are we going to feed nine billion people by 2050 ?

Could we increase crop production by expanding the amount of croplands? The answer to the question, is yes we could potentially increase the amount of arable farmland, but it would come at a prohibitive ecological cost. Most

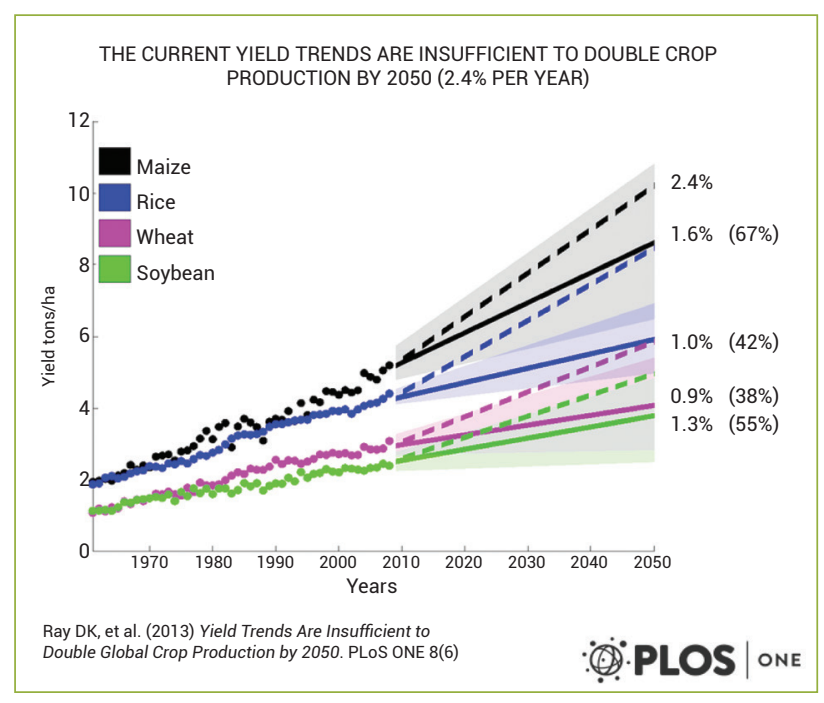

Figure 12. Actual trends for the rate of increases of crop yields for maize, rice, wheat, and soybean compared to the $2.4 \%$ rate increase required to feed nine billion people by 2050 (Ray et al. 2013).

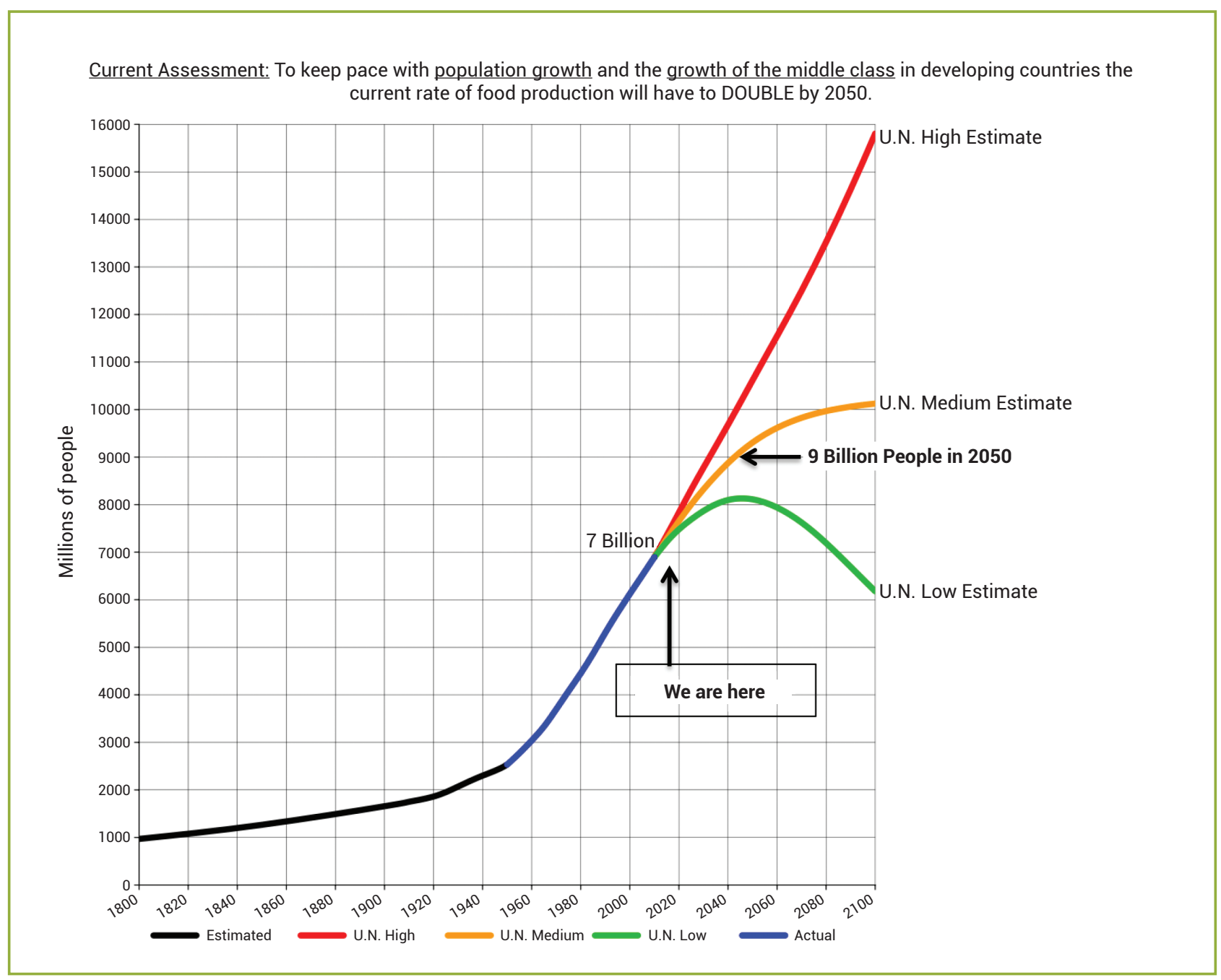

Figure 11. U.N. projections of human population growth to 2100 . 
potential croplands are what are termed "biodiversity hotspots." These biodiversity hotspots have already lost $70 \%$ of their original vegetation, yet they contain $50 \%$ of the world's plant species, which will disappear if we turn them all into farms. According to recent surveys, nearly $30 \%$ of all plant species have not even been discovered yet, and among these yet-to-be-discovered species may be plants that could hold the key to our survival in the future. We simply cannot afford to destroy the last remaining biodiversity hotspots on the planet.

Another factor limiting our ability to increase the area of arable land for food crops is competition with biofuels. In the United States, corn and cellulosic ethanol production are mandated to increase through 2025, and Brazil is planning to expand sugar production for ethanol by $60 \%$ by 2019 ; so the total amount of land dedicated to biofuel production is going to increase. This increase in arable land for biofuels will be at the expense of croplands. Yet another factor preventing the expansion of farmland is the loss of arable land due to urban sprawl, soil salination from irrigation, and desertification from over-grazing. In summary, expanding farmland is not a viable option. Only by doubling crop yields per hectare can we hope to feed nine billion people sustainably by 2050 .

But an even larger threat to agriculture looms on the horizon: global warming. If unchecked, climate change will pose big problems for agriculture in the future. The relentless burning of fossil fuels is releasing billions of tons of $\mathrm{CO}_{2}$ into the atmosphere every year, triggering a cascade of by now familiar environmental consequences. First, $\mathrm{CO}_{2}$ accumulation is causing a rise in global temperature due to the greenhouse effect, anywhere from 2 to $6^{\circ} \mathrm{C}$ by the end of the century. Rising temperatures will dry out forests leading to more forest fires, and forest fires release more $\mathrm{CO}_{2}$ to the atmosphere, raising the temperature still further. The thawing of permafrost in the arctic region will release vast amounts of additional carbon into the atmosphere, raising the temperature once again. The melting of Arctic ice will cause more sunlight to be absorbed by the ocean, raising its temperature even further. And if the ice sheets of Greenland and Antarctica melt, sea level would increase by $67 \mathrm{~m}(220 \mathrm{ft})$. Even partial melting could raise the sea level enough to submerge coastal areas, reducing the amount of arable land still further.

Global warming will also affect rainfall patterns. Some areas may receive greater than average rainfall, while others will receive less than normal rainfall. The subtropics are predicted to become drier, which will affect agricultural productivity. The melting of mountain glaciers would dry up rivers, devastating irrigation-dependent agriculture around the world, affecting billions of people. Finally, high temperatures will also have numerous direct deleterious effects on crop growth, including increased evapotranspiration rates, decreased germination rates, inhibition of photosynthesis, alteration of flowering times, inhibition of sexual reproduction (especially pollen tube development), and an increase in plant diseases and herbivore attacks. For every 1 degree Celsius rise in temperature, crop yields for wheat and rice are expected to decline by $10 \%$ and maize and soybean yields are expected to decrease by $17 \%$.

That's the bad news.

The good news is that plant biologists have never had such a stunning array of molecular tools at their disposal to tackle the twin challenges of population growth and climate change (Figure 13). Thanks to the rapid advances in DNA sequencing, we now have an ever-expanding database of genomes, transcriptomes, expression profiles, small RNAs, and epigenomes. These DNA and RNA databases can be correlated with proteomes, metabolomes, phenotypic data, QTLs, and expression level QTLs, which can help us to infer gene function. With a better understanding of gene function, we can potentially genetically engineer new traits into crops that will not only increase their yields, but will enable them to thrive even under the adverse conditions that may result from climate change, buying us needed time to stabilize the population at a sustainable level.

Currently, the major commercialized genetically modified crops involve relatively simple manipulations, such as the insertion of single genes for herbicide resistance or pest-insect toxins.

The next decade will likely see the development of combinations of desirable traits and the introduction of new traits such as nutritional improvements, resistance to viruses and pests, drought tolerance, and salt tolerance. Between 10 and 20 years from now, the technology for transforming with multiple genes will allow us to introduce various polygenic traits into crops, such as increasing nitrogen use efficiency and high temperature tolerance. By mid-century, when the population will reach nine billion, we may have succeeded in creating nitrogenfixing cereals, perennial cereals, and crops with increased photosynthetic efficiency.

It has long been a dream of humanity to improve plants in various ways and make them more productive, 


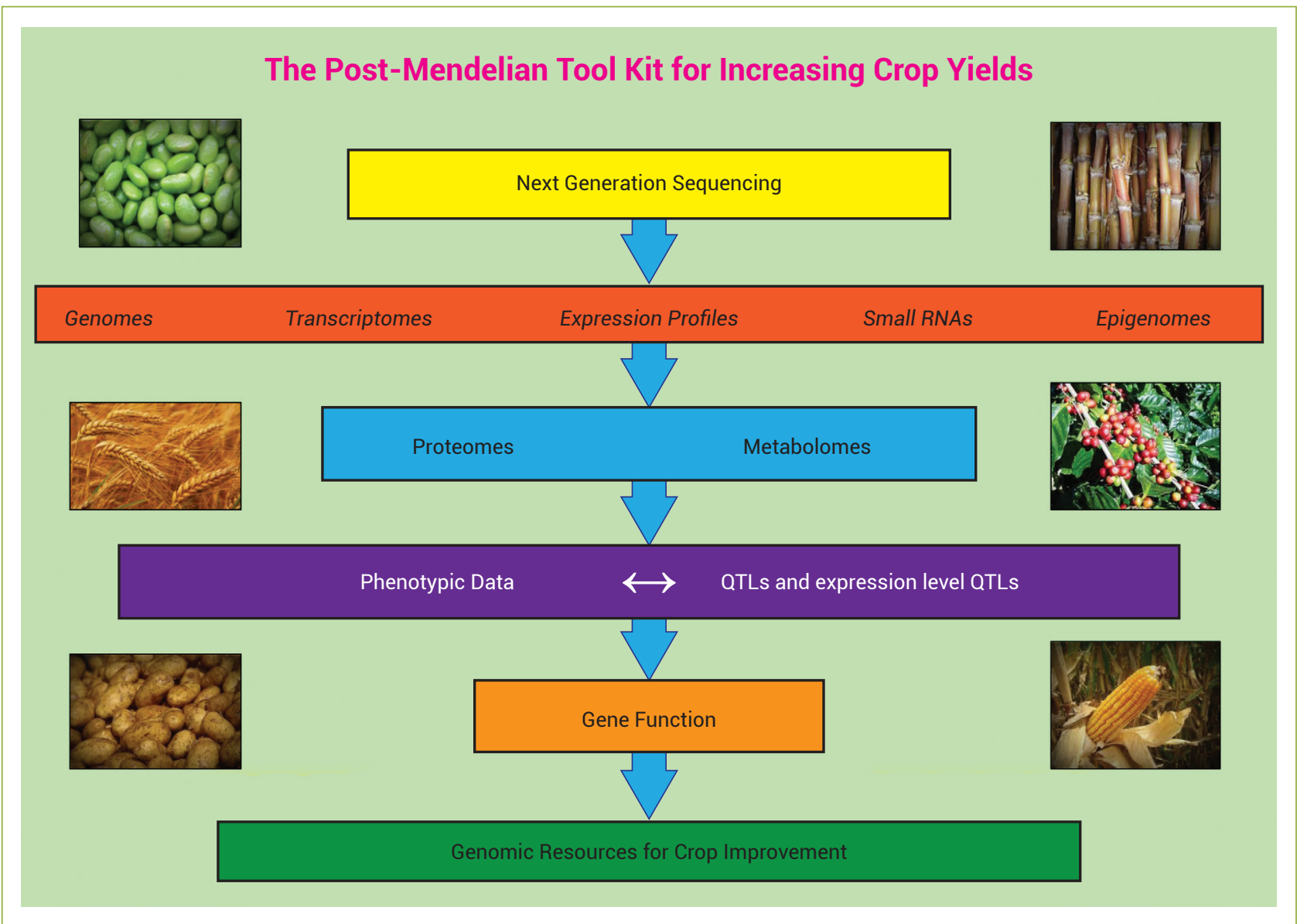

Figure 13. The new molecular tools available to increase crop yields per hectare, in the face of climate change.

attractive, or appealing. In the seventeenth century, Sir Francis Bacon, in his futuristic tract New Atlantis, made the following predictions:

We have large and various orchards and gardens... And we make by art in the same orchards and gardens, trees and flowers to come earlier or later than their seasons; and to come up and bear more speedily than by their natural course they do. We make them also by art greater much than their nature; and their fruit greater and sweeter and of differing taste, smell, colour, and figure, from their nature. And many of them so we order, as they become of medicinal use.

The prolific American plant breeder Luther Burbank was able to achieve many of the results that Bacon predicted. In a speech given in 1901, Burbank stated that:

Botanists once thought their classified species were more fixed and unchangeable than anything in heaven or earth that we can now imagine. We have learned that they are as plastic in our hands as clay in the hands of the potter or colors on the artist's canvas...

Over the past 60 years, however, we have come to appreciate that enhancements in agricultural productivity, by whatever means, comes at an environmental cost. This means we must use the new tools of molecular biology wisely — that is, sustainably - in order to reap the benefits. In the wise words of prominent molecular biologist Nina Federoff (2004):

Using our growing knowledge of plants and plant genes, and our increasing skill at modifying them with molecular techniques, we can make agriculture more focused and more productive - if we are careful. The thoughtful choice of genetic modifications can help us become better stewards of the earth. The key words here are careful and thoughtful. Whether the technology will be helpful or harmful, in the long run, depends on how it is used, on the choices people make. 


\section{REFERENCES}

Bommert P, Nagasawa NS, Jackson D (2013) Quantitative variation in maize kernel row number is controlled by the FASCIATED EAR2 locus. Nature Genetics 45:334-337.

Federoff N (2004) Mendel in the Kitchen. Washington, D.C.: Joseph Henry Press.

Evans LT (1998) Feeding the Ten Billion: Plants and Population Growth. Cambridge University Press.
Mazoyer M, Roudart L (2006) History of World Agriculture. J.M. Membrez, trans. Earthscan, London.

Olmstead AL, Rhode PW (2008) Creating Abundance: Biological Innovation and American Agricultural Development. Cambridge University Press.

Ray DK, Mueller ND, West PC, Foley JA (2013) Yield trends are insufficient to double global crop production by 2050 . PLOS ONE. 8(6):e66428. 